\title{
Chlorinated Polyethylene. II. Mechanisms of Chlorination
}

\author{
Bienvenu-Magloire Quenum, Philippe Berticat, and Georges Vallet \\ Laboratoire de Chimie Macromoléculaire, Université Claude Bernard \\ 43, Boulevard du 11 Novembre 1918-69621-Villeurbanne, France.
}

(Received June 17, 1974)

\begin{abstract}
The present paper deals with the mechanisms of photochlorination and thermal chlorination of polyethylene as influenced by the microtacticity evolution of the polymer under chlorination. The investigations have been carried out on a branched low-density polyethylene and a linear high-density polyethylene, both chlorinated under various conditions which enabled us to study the influences of the chlorination time, the chlorination temperature, the chlorination method, the solvents used, etc., on the mechanisms of chlorination. The high-resolution nuclear magnetic resonance analyses published elsewhere, $, 5,12$ the infrared spectroscopy, ${ }^{8}$ the ratios $(\mathrm{Cl} / \mathrm{C})$, and (number of $\mathrm{CHCl}$ units/number of $\mathrm{CH}_{2}$ units) and the degree of polymerization are the main results discussed.

KEY WORDS Chlorinated Polyethylene / Maximum Chlorine Content by Weight / Branched Low-Density Polyethylene / Linear High-Density Polyethylene / Syndiotacticity-Index / Heterotactic Tetrad / Photochlorination / Thermal Chlorination / Degree of Polymerization /
\end{abstract}

The nomenclature used by Huggins, et al., ${ }^{1}$ to describe the microstructure of vinyl-type polymers by infrared analysis is based on three repeated monomeric units, a triad. This nomenclature is misleading because it does not give a good representation of a heterotactic portion which would occur when a syndiotactic diad follows an isotactic diad (or the reverse). In this paper we will speak of a heterotactic tetrad instead of a heterotactic triad. The diagram here below represents a heterotactic tetrad of a vinyl-type polymer with its syndiotactic and isotactic parts. The short vertical bars stand for chlorine atoms<smiles>CCCCC(C)CCC(C)CCCC(C)C</smiles>

One can remark that the basic unit of polyvinyl syndiotacticity or isotacticity is the socalled diad (2 successive monomeric units) when the polyvinyl heterotacticity unit is the tetrad. One can speak of isotactic and syndiotactic polyvinyl sequences but it is impossible to do this for heterotacticity; the polyvinyl heterotacticity concept cannot be "extended" beyond the tetrad.
The nuclear magnetic resonance (NMR) nomenclature is quite different. In this case scientists use a structural description based on repeated carbon atoms: e.g., a triad means three repeated carbon atoms.

Although chlorinated polyethylene (CPE) has been commercially available since 1940 , no attempts have been made to elucidate the chlorination mechanisms connected with the polymer microtacticity evolution. Some authors have carried out a similar study, with poly(vinyl chloride) (PVC), because such an investigation was helpful in order to correlate microstructure with other properties. They ${ }^{2-4}$ made the following assumptions and conclusions:

The relative chlorination rate of a PVC sample depends on its microtacticity, but this influence does not continue through the subsequent crystallinity. $^{2}$

The highest chlorine contents by weight are rapidly obtained with the PVC samples containing the largest amount of heterotactic tetrads. ${ }^{2}$

During the first chlorination steps the heterotactic tetrads are preferentially chlorinated over the syndiotactic and isotactic sequences; the isotactic portions of the heterotactic tetrads are 
the chlorinated ones. ${ }^{3,4}$

Isotactic sequences $T G T G$ ( $T$ for the transconformation and $G$ for the gauche) and heterotactic tetrads TTTG give essentially $-\mathrm{CHCl}-$ $\mathrm{CHCl}-\mathrm{CHCl}-\mathrm{CHCl}-$ or $-\mathrm{CHCl}-\mathrm{CH}_{2}-$ $\mathrm{CHCl}-\mathrm{CHCl}-$ structures. $^{2}$

$-\mathrm{CHCl}-\mathrm{CH}_{2}-\mathrm{CCl}_{2}-\mathrm{CHCl}-$ structures are derived from heterotactic tetrads $T T G T, T T G^{\prime} T$ and from syndiotactic sequences $T T T T .^{2}$

The appearance of $-\mathrm{CHCl}-\mathrm{CHCl}-\mathrm{CHCl}-$ $\mathrm{CHCl}-$ and $-\mathrm{CHCl}-\mathrm{CH}_{2}-\mathrm{CCl}_{2}-\mathrm{CHCl}-$ structures increases the "stiffness" of the chlorinated polymer chains; thus the rotational energy of the system is transfered to the TTTTconformations of the unchlorinated PVC syndiotactic sequences, which rotate into easily chlorinated syndiotactic $T T G G$-conformations. ${ }^{4}$

In our previous papers ${ }^{5-7}$ the influence of the following parameters upon the microstructure and physical properties of CPE has been studied:

The nature of the initial polyethylene. ${ }^{5,7}$

The length of the chlorination time up to the maximum chlorine content by weight $(73 \%))^{7}$

The extension of the chlorination time beyond the minimum scheduled chlorination time necessary to obtain the 73-\% chlorine content level. ${ }^{5}$

The chlorination method. ${ }^{7}$

The chlorination temperature. ${ }^{6}$

The solvents used, ${ }^{6}$ etc.

Following these various CPE studies it is possible to investigate the photochlorination and thermal-chlorination mechanisms of polyethylene. The results obtained with $\mathrm{PVC}^{2-4}$ infrared, $^{8}$ and NMR analyses ${ }^{2-4}$ of the CPE samples will be sound bases on which to discuss the chlorination mechanisms proposed.

Although chlorination conditions have been described in our previous publications a brief repetition is given to allow a better understanding of this paper.

\section{EXPERIMENTAL}

\section{Initial Polymers}

The initial polymers are a branched lowdensity polyethylene (LDPE) and a linear highdensity polyethylene (HDPE). Their main characteristics are listed in Table I.

\section{Chlorination Conditions}

The photochlorinations are carried out either in suspension or in solution. In the first case either 1,1,2,2-tetrachloroethane (TCE) or carbon tetrachloride $\left(\mathrm{CCl}_{4}\right)$ is used as medium; in the second case only a TCE-solvent is used. The ultraviolet (UV) device is a Hanau Model Q 81/PL 321 mercury high-pressure system; its spectrum covers the UV wavelengths from 238 $\mathrm{nm}$ up to the visible wavelength at $579 \mathrm{~nm}$; the maximum of the supplied energy occurs at about $366 \mathrm{~nm}$ (see Table II).

The thermal chlorinations are carried out with TCE, in which the polymer is dissolved at $130^{\circ} \mathrm{C}$ and then heat-chlorinated, without any catalyst, at $90^{\circ} \mathrm{C}$ (LDPE) or $110^{\circ} \mathrm{C}$ (HDPE). These temperatures are the lowest ones which permit, in our conditions, the solution chlorination (or thermal chlorination) of the polymers owing to their respective crystallinity and initial concentration (5\%).

\section{Apparatus and Chlorination Agent}

The chlorination apparatus described elsewhere $^{9}$ has been improved for the thermal chlorination by the addition of 2 refrigerants. The chlorination agent is a dried (i.e., water

Table I. Characteristics of the initial polyethylene samples: low-density polyethylene (LDPE), branched polymer; high-density polyethylene (HDPE), linear polymer

\begin{tabular}{lcccccccc}
\hline & $\bar{M}_{n}{ }^{\mathrm{a}}$ & $\frac{\bar{M}_{w}{ }^{\mathrm{b}}}{\bar{M}_{n}}$ & $\frac{\mathrm{CH}_{3}{ }^{\mathrm{e}}}{\mathrm{CH}_{2}}$ & $\frac{\mathrm{CH}^{\mathrm{c}}}{\mathrm{CH}_{3}}$ & $\begin{array}{c}\text { Density, } \\
\mathrm{g} / \mathrm{cm}^{3}\end{array}$ & $\begin{array}{c}\text { Crystallinity, } \\
\%\end{array}$ & $T^{\circ}, \mathrm{C}^{\mathrm{d}}$ & \multicolumn{2}{c}{$\Delta H, \mathrm{cal} / \mathrm{g}^{\mathrm{e}}$} \\
\hline HDPE & 71600 & 13 & $4 \times 10^{-3}$ & - & 0.9821 & 79 & 111.5 & 58 \\
LDPE & 53200 & 10.6 & $3.2 \times 10^{-2}$ & $2.5 \times 10^{-1}$ & 0.9204 & 48 & 134.9 & 32.8 \\
\hline
\end{tabular}

a Dynamic osmotic measurements at $90^{\circ} \mathrm{C}$ in 1,2-dichlorobenzene.

b From GPC measurements.

c NMR analyses. ${ }^{17}$

a Melting temperatures.

- Heat of fusion. 
Table II. Main wavelengths of the UV-lamp and the supplied energy

\begin{tabular}{ccc}
\hline $\begin{array}{c}\text { Wavelength, } \\
\mathrm{nm}\end{array}$ & Intensity $^{\mathrm{a}}$ & $\begin{array}{c}\text { Energy, } \\
\text { kcal/einstein }\end{array}$ \\
\hline 265 & 19 & 107 \\
297 & 17 & 96 \\
302 & 30 & 94 \\
313 & 62 & 91 \\
366 & 100 & 78 \\
$405-408$ & 44 & 70 \\
436 & 71 & 65 \\
546 & 92 & 52 \\
$577-579$ & 79 & 49 \\
\hline
\end{tabular}

a The intensity values of the wavelengths have been given by the UV-lamp maker (Hanau). The other intensity values are less than 17 .

trace-free) commercial pure chlorine gas delivered into the chlorination medium at a constant flow rate $(2 l / \mathrm{hr})$ by a suitable system.

\section{RESULTS AND DISCUSSION}

Influence of the Chlorination Time up to the Maximum Chlorine-Content Level (73\%)

As can be seen in Table III a, b, c, d, contrary to the photochlorination case, the thermalchlorination process does not lead to a maximum chlorine-content level; whatever may be the parent-polymer the thermal-chlorination rate slows down when the chlorine content exceeds the $55-61-\%$ interval and a $65-\%$ or $67-\%$ chlorine-content level is reached.

This "limitation" of the thermal-chlorination process, observed in PVC by many scientists, has been explained on the basis of the chlorineradical energy, i.e., the energy supplied by the chlorination catalyst system. We think that the fundamental parameters linked to the chlorination energy could be the conformational and configurational changes occuring in the chlorinated polymer chains. ${ }^{8}$

Table IV lists the structures which can be detected $^{5,6,12}$ by high-resolution NMR analyses in the CPE samples' chains, for different chlorine contents and chlorination methods.

The microstructural evolutions of the branched polyethylene (LDPE) under the photochlorination process at $20^{\circ} \mathrm{C}$ in $\mathrm{TCE}$ and under the thermal-chlorination process at $90^{\circ} \mathrm{C}$ in $\mathrm{TCE}$ are represented respectively in Figure 1 (see Table IIIa) and in Figure 2 (see Table IIIc). The microstructural evolutions of the linear polyethylene (HDPE) during thermal chlorination at $110^{\circ} \mathrm{C}$ in $\mathrm{TCE}$ are shown in Figure 3 (see Table IIId).

As can be seen on these figures $(1,2$, and 3$)$, the thermal CPE microstructural evolutions and the photochlorinated CPE ones are different; but two main regions separated by the 56-61-\% chlorine-content interval can be identified:

The first region under the 56-61-\% chlorinecontent interval is characterized by the disappearance of the polyethylene sequences and

Table III-a. Branched polyethylene samples photochlorinated at $20^{\circ} \mathrm{C}$ in 1,1,2,2-tetrachloroethane (TCE) or in carbon tetrachloride $\left(\mathrm{CCl}_{4}\right)$

\begin{tabular}{ccccc}
\hline $\begin{array}{c}\text { Chlorination time, } \\
\text { min }\end{array}$ & 10 & 120 & 180 & 240 \\
\hline$T-\% \mathrm{Cl}_{2}{ }^{\mathrm{a}}$ & 55 & 72.3 & 73.2 & 73.3
\end{tabular}

\& Percentage of chlorine content by weight.

Table III-b. Linear polyethylene samples photochlorinated at $20^{\circ} \mathrm{C}$ in carbon tetrachloride $\left(\mathrm{CCl}_{4}\right)$

\begin{tabular}{ccccc}
\hline $\begin{array}{c}\text { Chlorination time, } \\
\text { min }\end{array}$ & 45 & 120 & 180 & 240 \\
\hline$T-\% \mathrm{Cl}_{2}{ }^{\mathrm{a}}$ & - & 47 & 65 & 72 \\
\hline
\end{tabular}

a Percentage of chlorine content by weight.

Table III-c. Branched polyethylene samples thermal chlorinated at $90^{\circ} \mathrm{C}$ in 1,1,2,2-tetrachloroethane (TCE)

\begin{tabular}{|c|c|c|c|c|c|c|c|c|}
\hline $\begin{array}{l}\text { Chlorination } \\
\text { time, min }\end{array}$ & 3 & 6 & 12 & 23 & 37 & 66 & 120 & 300 \\
\hline$T-\% \mathrm{Cl}_{2}^{\mathrm{a}}$ & & & & & & 62. & 4.7 & 65 \\
\hline
\end{tabular}

a Percentage of chlorine content by weight.

Table III-d. Linear polyethylene samples thermal chlorinated at $110^{\circ} \mathrm{C}$ in 1,1,2,2-tetrachloroethane (TCE)

\begin{tabular}{ccccccc}
\hline $\begin{array}{c}\text { Chlorination time, } \\
\text { min }\end{array}$ & 3 & 6 & 30 & 60 & 180 & 300 \\
\hline$T-\% \mathrm{Cl}_{2}{ }^{\mathrm{a}}$ & 6 & 41 & 56 & 61.7 & 64 & 67.1 \\
\hline
\end{tabular}

a Percentage of chlorine content by weight. 
Table IV. Triads and tetrads which can be detected in chlorinated polyethylene chains by high-resolution nuclear magnetic resonance (NMR)

\begin{tabular}{|c|c|c|}
\hline & Triads or Tetrads & $\tau$-Range \\
\hline$\alpha_{\mathrm{I}}$ & $\begin{array}{l}-\mathrm{CHCl}-\mathrm{CHCl}-\mathrm{CCl}_{2}- \\
-\mathrm{CH}_{2}-\mathrm{CHCl}-\mathrm{CCl}_{2}-\end{array}$ & $4.05-4.55$ \\
\hline$\alpha_{\text {II }}$ & $\begin{array}{l}-\mathrm{CHCl}-\mathrm{CHCl}-\mathrm{CHCl}- \\
-\mathrm{CHCl}-\mathrm{C} \underline{\mathrm{H}} \mathrm{Cl}-\mathrm{CH}_{2}-\end{array}$ & $4.55-5.35$ \\
\hline$\alpha_{\mathrm{III}}$ & $-\mathrm{CH}_{2}-\mathrm{CHCl}-\mathrm{CH}_{2}-$ & $5.35-6.05$ \\
\hline$\beta_{\mathrm{I}}$ & $\begin{array}{l}-\mathrm{CCl}_{2}-\mathrm{CH}_{2}-\mathrm{CCl}_{2}- \\
-\mathrm{CCl}_{2}-\mathrm{C} \mathrm{H}_{2}-\mathrm{CH}_{2}-\mathrm{CCl}_{2}-\end{array}$ & $6.05-6.45$ \\
\hline$\beta_{\text {II }}$ & $-\mathrm{CCl}_{2}-\mathrm{CH}_{2}-\mathrm{CHCl}-$ & $6.45-7.55$ \\
\hline$\beta_{\text {III }}$ & $-\mathrm{CHCl}-\mathrm{CH}_{2}-\mathrm{CHCl}-$ & $7.55-8.25$ \\
\hline$\beta_{\text {IV }}$ & $\begin{array}{l}-\mathrm{CHCl}-\mathrm{CH}_{2}-\left(\mathrm{CH}_{2}\right)_{n}-\mathrm{CHCl}- \\
n>4 \text {; sequence } \mathrm{PE}\end{array}$ & $8.25-8.95$ \\
\hline$\beta^{\prime}$ IV & $\begin{array}{l}-\mathrm{CH}_{2}-\mathrm{CH}_{2}-\mathrm{CHCl}- \\
-\mathrm{CH}_{2}-\mathrm{CH}_{2}-\mathrm{CH}_{2}-\mathrm{CHCl}- \\
-\mathrm{CH}_{2}-\mathrm{CH}_{2}-\mathrm{CCl}_{2}- \\
-\mathrm{CH}_{2}-\mathrm{CH}_{2}-\mathrm{CH}_{2}-\mathrm{CCl}_{2}-\end{array}$ & $8.25-8.55$ \\
\hline
\end{tabular}

the appearance of poly(vinyl chloride) triads $\left(\alpha_{\text {III }}\right.$ and $\left.\beta_{\text {III }}\right)$ and polyvinylidene triad or tetrad $\left(\beta_{\mathrm{I}}\right)$ and $\beta_{\text {IV }}^{\prime}$ structures (see Table IV).

In the second region, beyond the 56-61-\% chlorine content many interval, $\alpha_{\text {II }}$ and $\beta_{\text {II }}$ structures appear when the number of poly(vinyl chloride) sequences decreases.

We will consider each of these two regions.

First Region: $\varepsilon-\%$ to 55-61-\% Chlorine Content. The new structures $\alpha_{\text {III }}\left(\mathrm{CH}_{2}-\mathrm{CHCl}-\right.$ $\left.\mathrm{CH}_{2}\right), \beta_{\text {III }}\left(\mathrm{CHCl}-\mathrm{CH}_{2}-\mathrm{CHCl}-\right), \beta_{\mathrm{I}}\left(-\mathrm{CCl}_{2}-\right.$ $\mathrm{CH}_{2}-\mathrm{CCl}_{2}-$ or $-\mathrm{CCl}_{2}-\mathrm{CH}_{2}-\mathrm{CH}_{2}-\mathrm{CCl}_{2}-$ ), and $\beta^{\prime}{ }_{\mathrm{IV}} \quad\left(\mathrm{CHCl}-\left(\mathrm{CH}_{2}\right)_{2} ;-\mathrm{CHCl}-\left(\mathrm{CH}_{2}\right)_{3}\right.$; $\left.-\mathrm{CCl}_{2}-\left(\mathrm{CH}_{2}\right)_{3} ;-\mathrm{CCl}_{2}-\left(\mathrm{CH}_{2}\right)_{2}\right)$ are the results of the radical substitution of the methylenic $\left(\mathrm{CH}_{2}\right)$ hydrogen atoms by chlorine atoms.

It is well known in organic chemistry literatures that when a methylene $\left(\mathrm{CH}_{2}\right)$ of an alkane is changed into a chloromethylene $(\mathrm{CHCl})$ group, the chlorine atom introduces a negative inductive effect $(-\mathrm{I})$ and a mesomeric effect $(+\mathrm{M}) .{ }^{10}$ The - I effect prevails in the suspension $\left(20^{\circ} \mathrm{C}\right)$ photochlorination process of polyethylene. - $\mathrm{CHCl}$-units appear, from the beginning of the reaction, at $\beta$ positions with respect to each other and give $\alpha_{\text {III }}$ and $\beta_{\text {III }}$ triads. As the photochlorination is carried out in a suspension medium, these - $\mathrm{CHCl}$-units begin to appear in the polymer amorphous phase in which the chlorine-radical concentration is high.

The $\beta_{\text {IV }}^{\prime}$ structures are monochloropropane (- $\left.\mathrm{CHCl}-\left(\mathrm{CH}_{2}\right)_{2}-\right)$ and 1,1-dichloropropane $\left(-\mathrm{CCl}_{2}-\left(\mathrm{CH}_{2}\right)_{2}-\right)$ or monochlorobutane $\left(-\mathrm{CHCl}-\left(\mathrm{CH}_{2}\right)_{3}-\right)$ and 1,1-dichlorobutane $\left(-\mathrm{CCl}_{2}-\left(\mathrm{CH}_{2}\right)_{3}-\right)$. On the thermal CPE samples' NMR spectra these two different structures (mono and dichloro) of either type (propane or butane) are not separable from each other. But if the $\beta_{\text {IV }}^{\prime}$ monochloro structures were present in large amount, $\alpha_{\mathrm{III}}\left(\mathrm{CH}_{2}-\mathrm{CHCl}-\mathrm{CH}_{2}\right)$ triads would appear on the NMR spectra from the beginning of the reaction and not from the 20-25-\% chlorine-content interval (Figures 2 and 3). In addition, the thermal CPE samples with chlorine-content value up to $33 \%$ still have melting points, ${ }^{11}$ which indicates the presence of unchlorinated polyethylene sequences of relatively important lengths. If the chlorineradicals gave $-\mathrm{CHCl}-$ units instead of $\mathrm{CCl}_{2}$ units, there would be $1-\mathrm{CHCl}-$ unit for 5 $-\mathrm{CH}_{2}$ - units in the chain of a 33-\% thermal CPE sample; such a product would not keep crystallinity and melting points could not be detected. But if polyvinylidene triad or tetrads $\left(\beta_{\mathrm{I}}\right)$ were wholly responsible for the chlorine content of a 33-34-\% CPE sample, there would be $2-\mathrm{CCl}_{2}-$ units for $20-\mathrm{CH}_{2}-$ units and the 33-34-\% thermal CPE sample would keep crystallinity.

The above considerations lead to the conclusion that under $33-\%$ chlorine content by weight, the $\beta_{\mathrm{IV}}$ dichloro structures are present in large amount in the thermal CPE chains. Thus in the thermal-chlorination process of polyethylene, during the first reaction-steps, contrary to what occurs during the photochlorination process, the mesomeric $(+\mathrm{M})$ effect of the chlorine atom of a $-\mathrm{CHCl}-$ unit prevails against its $-\mathrm{I}$ effect and gem substitutions take place at $\beta$ or $\gamma$ position:

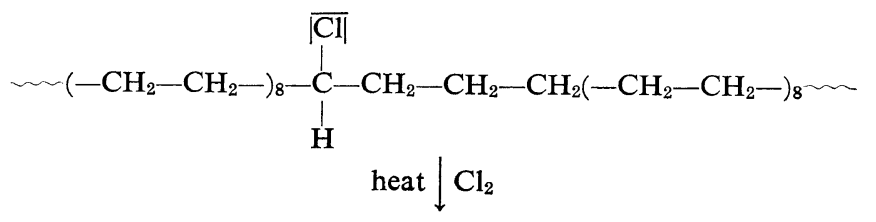


Chlorinated Polyethylene. II.

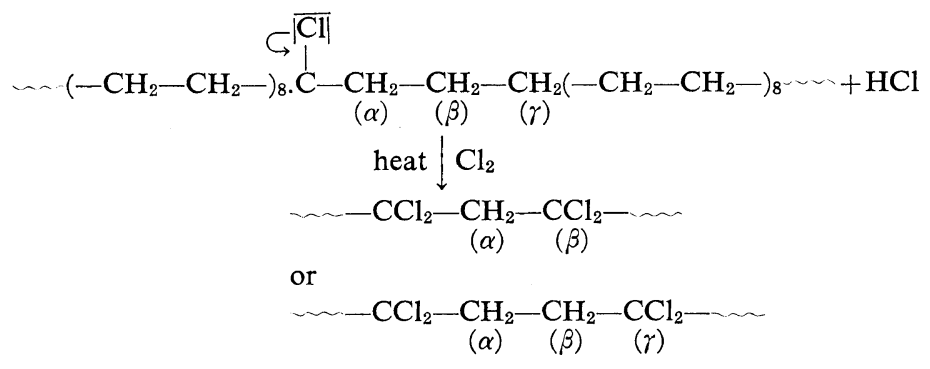

As can be seen in Table $\mathrm{V}$, these gem substitutions occur, in the thermal process, whatever may be the parent polymer (branched or linear); in addition many initial methyl $\left(\mathrm{CH}_{3}\right)$ groups can still be detected in the thermal (branched) CPE samples up to a $33-\%$ chlorine content value. ${ }^{12}$ Thus, one could state that these gem substitutions do not take place preferentially at the branching points of a branched parent-polymer.

When $\alpha_{\text {III }}$ and $\beta_{\text {III }}$ triads, i.e., PVC triads, begin to appear, the thermal-chlorination substitution mechanism takes place randomly; the thermal CPE samples become amorphous when the $33-\%$ chlorine-content value is exceeded. ${ }^{11,12}$ The thermal CPE's polymeric chains made from the branched parent-polymer (LDPE) contain, when the chlorine content limit is obtained, a very little amount of $\beta_{\mathrm{II}}\left(-\mathrm{CHCl}-\mathrm{CH}_{2}-\mathrm{CCl}_{2}-\right)$ structure, which means that the proportions of polyvinyl heterotactic tetrads $T T G T, T T G^{\prime} T$, and polyvinyl syndiotactic sequences TTTT are almost negligible when the PVC triads $\alpha_{\text {III }}$ and $\beta_{\text {III }}$ have reached their maximum length at the 61-\% chlorine content (Figure 2).

On the contrary, after a $4-$ to 5 -hr chlorination time, $\beta_{\mathrm{II}}$ and $\alpha_{\mathrm{II}}(-\mathrm{CHCl}-\mathrm{CHCl}-\mathrm{CHCl}-$ or $-\mathrm{CH}_{2}-\mathrm{CHCl}-\mathrm{CHCl}-$ ) structures are present in large amount in the chains of the photochlorinated (branched) CPE samples or the photochlorinated (linear) CPE samples ${ }^{5}$ and the thermal-chlorinated (linear) CPE samples, which indicates that PVC heterotactic tetrads TTGT, $T T G^{\prime} T$, and $T T T G$, and PVC syndiotactic sequences $T T T T$ were present in large quantity when the PVC sequences reached their maximum length (Figures 1 and 3).

The syndiotacticity-index values, $S$-values

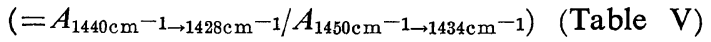
are almost constant in thermal CPE samples made from the branched polymer, while there is a steady progression in thermal CPE samples produced from the linear polyethylene and in the photochlorinated CPE samples produced from the branched polymer. But in all three cases, up to the 56-61-\% chlorine-content interval, the $S$-values are less than 1 , which indicates a slight prevalence of PVC isotactic sequences of TGTG conformations over PVC syndiotactic sequences of TTTT conformations, ${ }^{8}$ although their respective molar extinction coefficients are different.

The slight difference between the proportions of $\alpha_{\text {III }}\left(-\mathrm{CH}_{2}-\mathrm{CHCl}-\mathrm{CH}_{2}-\right)$ and $\beta_{\mathrm{III}}(-\mathrm{CHCl}-$ $\left.\mathrm{CH}_{2}-\mathrm{CHCl}-\right)$ triads, when they appear, indicates that the PVC sequences are separated by other structures which are polyethylene sequences in the photochlorinated CPE samples and $\beta^{\prime}{ }_{1 V}$ structures and/or polyethylene sequences in the thermal CPE samples. When the $\alpha_{\text {III }}$ and $\beta_{\text {III }}$ triads proportions are equal, i.e., when the PVC sequences have reached their maximum length, polyethylene sequences have disappeared in all the CPE samples (whatever may be the chlorination method). The same occurs for $\beta^{\prime}{ }_{\text {IV }}$ structures in the case of the liner thermal-chlorinated polyethylene (see Figure 3).

The above considerations lead to the following conclusions about the configurational and conformational changes occurring in the first region ( $\varepsilon$ to $56-61-\%$ chlorine content):

During the photochlorination process of the branched polyethylene and the thermal chlorination of the linear polyethylene the syndiotactic and isotactic PVC sequences which appear alternate regularly to give numerous heterotactic tetrads $T T T G, T T G T$, and $T T G^{\prime} T$. The syndiotactic and isotactic PVC sequences are long in the case of the thermal-chlorinated (linear) CPE samples; this deduction is consistent with the fact that-as can be seen in Figures 1 and 3- 
Table V. Characteristics of the chlorinated polyethylene samples

\begin{tabular}{|c|c|c|c|c|c|c|c|c|c|c|c|}
\hline $\begin{array}{l}\text { Chlorina- } \\
\text { tion time, } \\
\text { min }\end{array}$ & $\underset{\%}{\text { Yield, }}$ & $\begin{array}{l}T-\% \\
\mathrm{Cl}_{2}{ }^{\mathrm{b}}\end{array}$ & $\frac{\mathrm{Cl}}{\mathrm{C}}$ & $\frac{\mathrm{nb} \mathrm{CHCl}}{\mathrm{nb} \mathrm{CH}_{2}}$ & $\underset{\%}{-\mathrm{CHCl}}-$ & $-\underset{\%}{\mathrm{CH}_{2}-}$ & $-\frac{\mathrm{CCl}_{2}-}{\%}$ & $\begin{array}{l}\text { Syndio- } \\
\text { tacticity } \\
\text { Index, } S\end{array}$ & $\overline{\mathrm{DP}}_{n}$ & $\begin{array}{l}\bar{M}_{n}, \\
10^{-3}\end{array}$ & $\begin{array}{l}\text { Den- } \\
\text { sity, }^{c} \\
\text { g/cm }\end{array}$ \\
\hline \multicolumn{12}{|c|}{ Samples from branched polymer thermal chlorinated at $90^{\circ} \mathrm{C}$ in TCE } \\
\hline 3 & 95 & 24 & 0.123 & $\varepsilon$ & $\varepsilon$ & 94 & 5 & 0.86 & 1000 & 36 & 0.9618 \\
\hline 6 & 95 & 33 & 0.190 & 0.07 & 6.1 & 87.4 & 6.5 & 0.87 & 1580 & 65 & - \\
\hline 12 & 96 & 38 & 0.237 & 0.11 & 9.2 & 83.6 & 7.2 & 0.88 & 1800 & 80 & 1.0350 \\
\hline 23 & 98 & 54.5 & 0.460 & 0.38 & 22.5 & 59.2 & 18.3 & 0.89 & 1760 & 105 & 1.3575 \\
\hline 37 & - & 61.5 & 0.600 & 0.44 & 25.2 & 57.3 & 17.5 & 0.88 & 1310 & 91 & - \\
\hline 66 & 94 & 63 & 0.635 & 0.80 & 39 & 48.7 & 12.3 & 0.86 & 1320 & 95 & 1.4315 \\
\hline 120 & 94 & 65 & 0.685 & 1.31 & 51 & 39 & 10 & - & 1065 & 90 & 1.4470 \\
\hline \multicolumn{12}{|c|}{ Samples from the linear polymer thermal chlorinated at $110^{\circ} \mathrm{C}$ in $\mathrm{TCE}$} \\
\hline 3 & 95 & 6 & 0.027 & $\varepsilon$ & $\varepsilon$ & 98 & 1.2 & - & 1500 & 45 & 0.9890 \\
\hline 6 & 95 & 41 & 0.270 & 0.114 & 9.35 & 32 & 8.65 & 0.55 & 1810 & 85 & 1.1080 \\
\hline 30 & 94 & 56 & 0.495 & 0.483 & 29.5 & 61.5 & 9 & 0.66 & 1360 & 85 & 1.3098 \\
\hline 60 & 90 & 61.7 & 0.600 & 1.27 & 54.2 & 42.6 & 3.2 & 1.11 & 1000 & 68 & 1.4048 \\
\hline 180 & 80 & 64 & 0.640 & 1.975 & 66 & 44.3 & 0.7 & 1.73 & 595 & 43 & 1.4190 \\
\hline 300 & 77 & 67.1 & 0.770 & 2.66 & 66.6 & 25.5 & 8.4 & 1.06 & 328 & 25 & 1.4898 \\
\hline
\end{tabular}

Samples from the branched polymer photochlorinated at $20^{\circ} \mathrm{C}$ in TCE

\begin{tabular}{|c|c|c|c|c|c|c|c|c|c|c|c|}
\hline 2.30 & 99 & 16 & 0.075 & 0.111 & 10 & 90 & 0 & 0.77 & 1270 & 43 & 0.9510 \\
\hline 4 & 99 & 46 & 0.326 & 0.266 & 19.7 & 74 & 6.3 & 0.81 & 1320 & 67 & 1.0850 \\
\hline 10 & 96 & 55 & 0.467 & 0.316 & 22.6 & 71.5 & 5.9 & 0.96 & 2750 & 127 & - \\
\hline 20 & 95 & 60.5 & 0.580 & 0.9 & 44.8 & 49.7 & 5.5 & 0.88 & 2930 & 200 & 1.2170 \\
\hline 60 & 80 & 67.5 & 0.775 & 1.88 & 59 & 31.3 & 9.7 & 2.00 & 2220 & 181 & 1.4150 \\
\hline 105 & 78 & 68.4 & - & - & 一 & - & - & 2.23 & - & - & - \\
\hline 120 & 75 & 71 & 0.900 & 2 & 58.7 & 29.3 & 12 & 2 & 660 & 60 & - \\
\hline 240 & 75 & 73 & 1 & 2.7 & 57.8 & 21.4 & 20.8 & 1.82 & 620 & 60 & 1.6615 \\
\hline
\end{tabular}

a Yield of the chlorination process, i.e., amount of the chlorinated product obtained relative to the amount of the initial polymer.

b Percentages of chlorine content by weight.

c Densities measured with a Davenport column gradient. ${ }^{5}$

equality between the $\alpha_{\text {III }}$ and $\beta_{\text {III }}$ triads is obtained at $56-\%$ against $61-\%$ chlorine content for the photochlorinated CPE. The vinyl heterotactic tetrads are less numerous in the linear polyethylene thermally chlorinated at $56 \%$ than in the branched polyethylene photochlorinated at $61 \%$.

During the thermal-chlorination process of the branched polyethylene, the PVC sequences which appear are long TGTG isotactic ones alternating with short TTTT syndiotactic ones to give very few TTTG heterotactic tetrads when the 61-\% chlorine-content value is reached (Figure 2).

These important conclusions will be helpful, later on, to explain the chlorination mechanism occurring beyond the $56-61-\%$ chlorine-content interval.

In the first region, under the 56-61-\% chlorine-content interval and from the beginning of the chlorination process, there are chainbreakages along with the radical substitution mechanism (see Table V). These chain-breakages are rapidly screened, as the chlorination proceeds, by chain-reticulations which lead to number-average molecular weights $\left(\bar{M}_{n}\right)$ or degrees of polymerization $\left(\overline{\mathrm{DP}}_{n}\right)$ larger than the initial ones of the parent-polymers. The highest $\bar{M}_{n}$ or $\overline{\mathrm{DP}}_{n}$ is obtained in the photochlorination process; in this case the reticulations are made easily since the reaction is carried out in a 
Chlorinated Polyethylene. II.

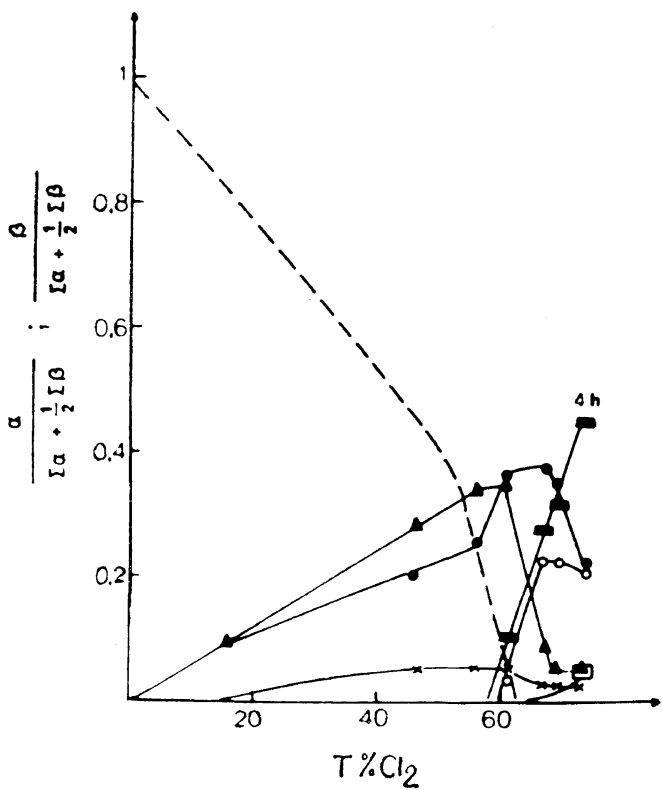

Figure 1. NMR analyses of triads of photochlorinated LDPE in suspension.

$$
\begin{aligned}
& --, \mathrm{PE}\left(-\mathrm{CH}_{2}-\mathrm{CH}_{2}-\mathrm{CH}_{2}-\mathrm{CH}_{2}-\right), \beta_{\mathrm{IV}} \text {; } \\
& \triangle,-\mathrm{CHCl}-\mathrm{CH}_{2}-\mathrm{CHCl}-, \beta_{\mathrm{III}} \text {; } \\
& \text {-, }-\mathrm{CH}_{2}-\mathrm{CHCl}-\mathrm{CH}_{2}-, \alpha_{\mathrm{III}} \text {; } \\
& \times,\left\{-{ }_{-\mathrm{CCl}_{2}-\mathrm{CH}_{2}-\mathrm{CH}_{2}-\mathrm{CCl}_{2}-}-\mathrm{CH}_{2}-\mathrm{CCl}_{2}-\right\}, \beta_{\mathrm{I}} \text {; } \\
& \text { a, }\left\{\begin{array}{l}
-\mathrm{CHCl}-\mathrm{CHCl}-\mathrm{CHCl}- \\
-\mathrm{CH}_{2}-\mathrm{CH} \mathrm{Cl}-\mathrm{CHCl}-
\end{array}\right\}, \alpha_{\mathrm{II}} ; \\
& \text { घ, }\left\{\begin{array}{l}
-\mathrm{CH}_{2}-\mathrm{CH}_{2}-\mathrm{CH}_{2}-\mathrm{CHCl}_{2}- \\
-\mathrm{CH}_{2}-\mathrm{CH}_{2}-\mathrm{CH}_{2}-\mathrm{CHCl}- \\
-\mathrm{CH}_{2}-\mathrm{CH}_{2}-\mathrm{C} \mathrm{CHCl}_{2}- \\
-\mathrm{CH}_{2}-\mathrm{CH}_{2}-\mathrm{CHCl}-
\end{array}\right\}, \beta^{\prime}{ }_{\mathrm{IV}} ; \\
& \mathrm{O},-\mathrm{CCl}_{2}-\mathrm{CH}_{2}-\mathrm{CHCl}-, \beta_{\mathrm{II}} \text {; } \\
& \square,\left\{\begin{array}{l}
-\mathrm{CCl}_{2}-\mathrm{CH} \mathrm{H}-\mathrm{Cl}-\mathrm{CHCl}- \\
-\mathrm{CCl}_{2}-\mathrm{C} \mathrm{H} C l-\mathrm{CH}_{2}-
\end{array}, \alpha_{\mathrm{I}} .\right.
\end{aligned}
$$

suspension medium. On the other hand, besides the fact that the reaction is carried out in solution, it appears that in the thermal-chlorination process, the $-\mathrm{CCl}_{2}-$ units and the initial methyl groups of the polymer ${ }^{12}$ play a hindering role and prevent any close contact between the thermal-chlorinated chains, thus limiting the reticulations. Owing to the high yield, $Y-\%$, of the chlorination operations (Table V) the $\bar{M}_{n}$ increase cannot be attributed to a fractionation of the CPE samples during their recovery from the chlorination mixture. ${ }^{8}$ It is important to notice that the initial chain-breakages take place whatever may be the parent-polymer, which indicates that the branching points are not specially concerned.

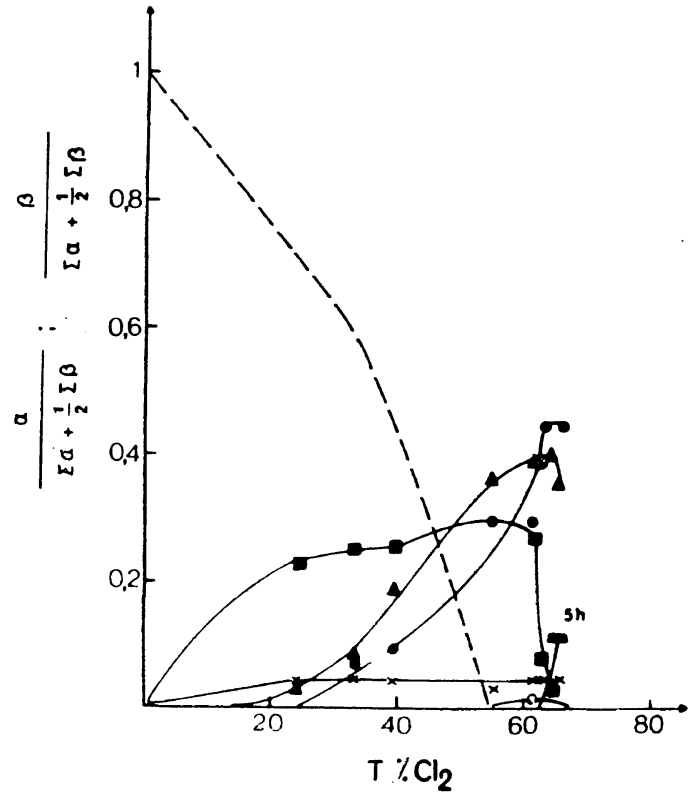

Figure 2. NMR analyses of triads LDPE heat chlorinated is solution. Notations are the same as those in Figure 1.

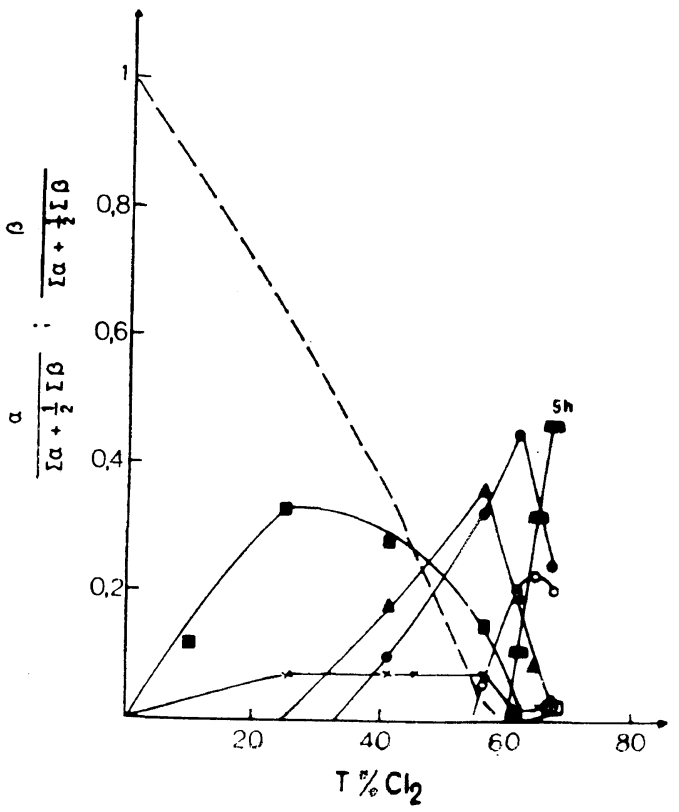

Figure 3. NMR analyses of triads of HDPE heat chlorinated in solution. Notations are the same as those in Figure 1.

Second Region: 56-61-\% to 73-\% Chlorine Content. From the 56-\% up to the $64-\%$ chlorine content value, for thermal CPE samples 
produced from the linear polyethylene, and from the $60.5-\%$ up to the $68.4-\%$ chlorine content value, for photochlorinated CPE samples, the increase of the syndiotacticity index, $S,^{8}$ is enhanced (Table V), which means an absorbance increase of the PVC syndiotactic sequences present in the chlorinated polymeric chains. ${ }^{8}$ This absorbance increase cannot be attributed to the appearance of new PVC syndiotactic sequences because, as can be seen in Figures 1 and 3, the proportion of the PVC sequences decreases; therefore this absorbance increase of the PVC syndiotactic sequences can only be the result of the chlorination of the isotactic portions of the PVC heterotactic tetrads, which increases the length of the syndiotactic sequences.

This chlorination can be explained through the two mechanisms described below:

(a) Radical substitution.

$$
\begin{aligned}
& -\mathrm{CHCl}-\mathrm{CH}_{2}-\mathrm{CHCl}-\quad-\mathrm{CHCl}-\underset{(\mathrm{I})}{\mathrm{C}} \mathrm{H}-\mathrm{CHCl}-+\mathrm{HCl} \\
& \stackrel{\mathrm{Cl}_{2}}{\longrightarrow} \\
& \text { UV } \overrightarrow{\text { or heat }} \\
& -\mathrm{CHCl}-\mathrm{CH}_{2}-\mathrm{CHCl} \longrightarrow \longrightarrow-\mathrm{CCl}-\mathrm{CH}_{2}-\mathrm{CHCl}-+\mathrm{HCl} \\
& \text { (II) } \\
& -\mathrm{CHCl}-\underset{(\mathrm{I})}{\mathrm{CH}}-\mathrm{CHCl}-\longrightarrow-\mathrm{CHCl}-\mathrm{CHCl}-\mathrm{CHCl}-+\mathrm{Cl} \text {. } \\
& \stackrel{\mathrm{Cl}_{2}}{\longrightarrow} \\
& -. \mathrm{CCl}-\mathrm{CH}_{2}-\mathrm{CHCl}-\longrightarrow-\mathrm{CCl}_{2}-\mathrm{CH}_{2}-\mathrm{CHCl}-+\mathrm{Cl} \text {. } \\
& \text { (II) }
\end{aligned}
$$

It must be noticed that the $+\mathrm{M}$ effect of the chlorine atom favors the appearance of the radical II (-. CCl- $\mathrm{CH}_{2}-\mathrm{CHCl}-$ ).

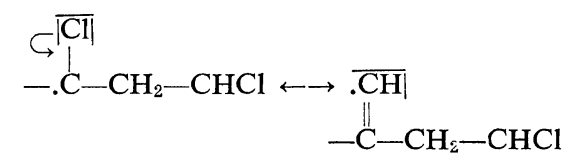

(b) Dehydrochlorination followed by the chlorination of the double bonds.

$$
\begin{aligned}
& -\mathrm{CHCl}-\mathrm{CH}_{2}-\mathrm{CHCl}-\longrightarrow-\mathrm{CHCl}-. \mathrm{CH}-\underset{(\mathrm{I})}{\mathrm{CHCl}-}+\mathrm{HCl} \\
& \text { UV } \stackrel{\mathrm{Cl}_{2}}{\underset{\text { or heat }}{\longrightarrow}} \\
& -\mathrm{CHCl}-. \mathrm{CH}-\mathrm{CHCl}-\longrightarrow-\mathrm{CHCl}-\mathrm{CH}=\underset{\text { (II) }}{\mathrm{CH}}-+\mathrm{Cl} \text {. }
\end{aligned}
$$

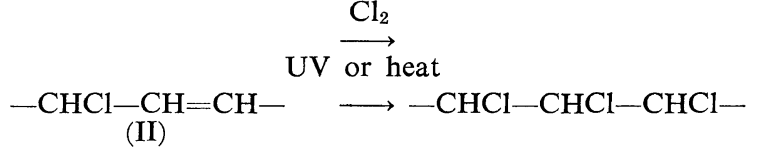

The radical substitution mechanism leads to $\alpha_{\text {II }}\left(-\mathrm{CHCl}-\mathrm{CHCl}-\mathrm{CHCl}-\right.$ or $-\mathrm{CH}_{2}-\mathrm{CHCl}-$ $\mathrm{CHCl}-$ ) and $\beta_{\mathrm{II}}\left(-\mathrm{CHCl}-\mathrm{CH}_{2}-\mathrm{CCl}_{2}-\right)$ triads, which the dehydrochlorination mechanism gives only $\alpha_{\text {II }}$ structures. As these mechanisms take place at the isotactic portions of the heterotactic tetrads, the occurence of the dehydrochlorination mechanism is not easy because the concerned carbon-atoms are not planar to each other.
Thus, in the chlorine interval we are investigatings, i.e., $56-64-\%$ for the thermal chlorination of the linear polymer (Figure 3) and 60.5-68.4-\% for the photochlorination of the branched polyethylene (Figure 1), the radical substitution mechanism prevails over the dehydrochlorination and chlorination mechanism. The degradation of the polymer under chlorination up to carbonisation, which occurs when the chlorine- 
gas concentration decreases in the chlorination medium, is proof that the dehydrochlorination process cannot be omitted and takes place slightly along with the radical substitution.

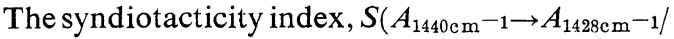

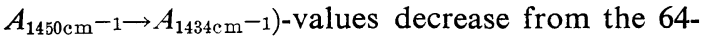
$\%$ thermal chlorinated (linear) CPE sample (Figure 3) and from the 68.4-\% photochlorinated (branched) CPE sample (Figure 1). This $S$ values' decrease (Table V) means an absorbance decrease of the PVC syndiotactic sequences, ${ }^{8}$ which indicates that the PVC syndiotactic sequences are chlorinated preferentially v.s., the PVC isotactic sequences through the two mechanisms described below:

(a) Rotation of the short PVC syndiotactic sequences TTTT into TTGG, which are chlorinated easily through a radical substitution of the methylenic hydrogen atoms of their $G G$ portion (see Figure 11a of part I of this series ${ }^{8}$ ).

(b) Dehydrochlorination followed by the chlorination of the double bonds directly on the PVC syndiotactic sequences TTTT.

We can state that the first mechanism prevails in the photochlorination process. This important conclusion, which confirms an assumption made by Allen and Young, ${ }^{4}$ is consistent with the following results and considerations:

The plot of $A_{615} / A_{660 \rightarrow 685} v . s .$, chlorine content, a measurement of the proportion between $T$ - and $G$-conformation, ${ }^{8}$ for the photochlorinated CPE samples, shows a sharp decrease from the 67.5-\% chlorine-content value, which indicates a growth of the $G$-conformation proportion in the photochlorinated polymeric chains (see Figure 12 and Table II of Part I of this series ${ }^{8}$.

This growth of the $G$-conformation proportion can be regarded as the result of the isomerisation of the short PVC syndiotactic sequences TTTT into TTGG. At the 68.4-\% chlorine content the large amount of $\alpha_{\text {II }}(-\mathrm{CHCl}-$ $-\mathrm{CHCl}-\mathrm{CHCl}-$ or $\left.-\mathrm{CH}_{2}-\mathrm{CHCl}-\mathrm{CHCl}-\right)$ and $\beta_{\mathrm{II}}\left(-\mathrm{CHCl}-\mathrm{CH}_{2}-\mathrm{CCl}_{2}-\right.$ ) structures present in the polymeric chains increase their stiffness, as proved by dynamic mechanical properties studies, ${ }^{12}$ and the rotation energy of the "system" is transferred to the short PVC syndiotactic sequences $T T T T$, which rotate into $T T G G$-ones.

The dehydrochlorination process prevails with the thermal chlorination of the linear polyethylene and is favored by the presence of a certain amount of long PVC syndiotactic sequences TTTT in the chlorinated polymeric chains, which permit the dehydrochlorination process to be a "zip" one and thus give long $\alpha_{\text {II }}$ structures. At the same chlorine content by weight, beyond the 56-61-\% chlorine-content interval (Table V), the ratio, $\mathrm{nb} \mathrm{CHCl} / \mathrm{nb} \mathrm{CH}_{2}$, in a thermal (linear) CPE sample is larger than in a thermal (branched) CPE or a photochlorinated CPE sample.

When $\alpha_{\text {II }}$ and $\beta_{\text {II }}$ structures begin to appear chain-breakages occur; they are more numerous when the "zip" dehydrochlorination process takes place (Table V). The "zip" mechanism does not occur with the PVC isotactic sequences TGTG; ${ }^{13}$ thus when the long PVC syndiotactic sequences TTTT are almost completely chlorinated, the energy supplied by the heat is not sufficient to rotate the short PVC syndiotactic sequences TTTT into TTGG-ones and the chlorine content of the thermal CPE reaches a level $(65-67-\%)$ below the maximum level (73\%).

Influence of the Chlorination Time beyond the Minimum Scheduled to Obtain the 73-\% Chlorine Level

During the photochlorination process a new mechanism takes place when the chlorination time is extended beyond the minimum necessary to obtain the 73-\% chlorine level, i.e., beyond $2 \mathrm{hr}$ for the branched polymer and beyond $4 \mathrm{hr}$ for the linear polyethylene. ${ }^{5}$ The characteristics of this mechanism are:

the decrease of the $\overline{\mathrm{DP}}_{n}$;

the increase of the ratio, $\mathrm{nb} \mathrm{CHCl} / \mathrm{nb} \mathrm{CH}_{2}$, while the ratio, $\mathrm{Cl} / \mathrm{C}$, is still constant and equal to 1 .

the decrease of the proportions of $\alpha_{I I I}, \beta_{I I I}$, and $\beta_{\text {II }}$ structures while those of $\alpha_{\text {II }}$ and $\alpha_{\text {I }}$ increase. ${ }^{5}$ This mechanism is a rearrangement one:
(1)

$$
\begin{gathered}
-\mathrm{CHCl}-\mathrm{CH}_{2}-\mathrm{CCl}_{2}- \\
\qquad \underset{+\mathrm{HCl}}{\stackrel{\mathrm{HCl}}{\rightleftarrows}}
\end{gathered}
$$




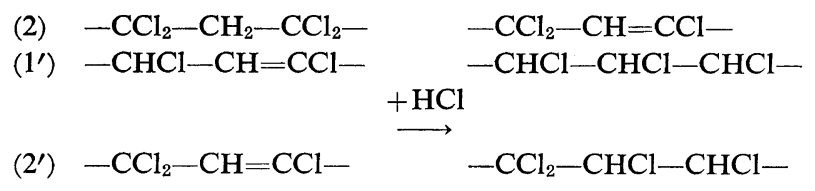

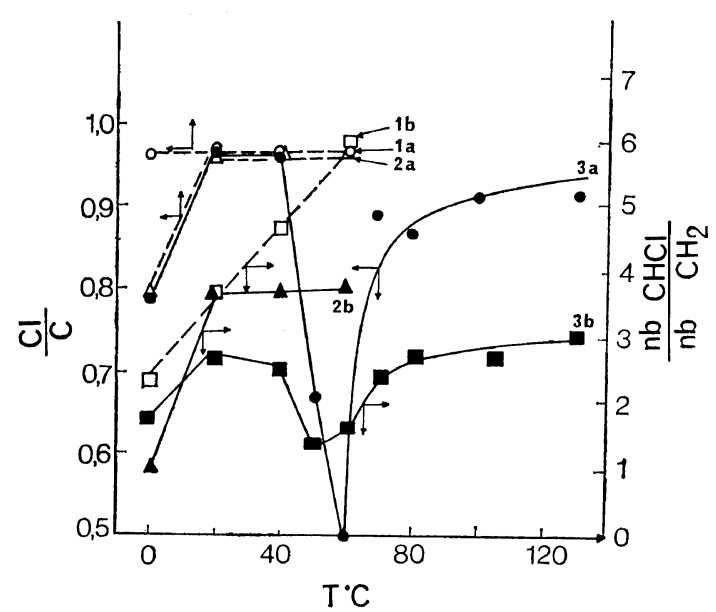

Figure 4. Comparison of the plots of the ratios $(\mathrm{Cl} / \mathrm{C})$ and $\left(\mathrm{nb} \mathrm{CHCl} / \mathrm{nb} \mathrm{CH}_{2}\right.$ ) of branched (LDPE) and linear (HDPE) polyethylenes samples photochlorinated at different temperatures in carbon tetrachloride $\left(\mathrm{CCl}_{4}\right)$ or 1,1,2,2-tetrachloroethane (TCE) for $4 \mathrm{hr}$.

$$
\frac{\mathrm{Cl}}{\mathrm{C}}
$$

1a. LDPE $\left(\mathrm{CCl}_{4}\right)$

2a. HDPE $\left(\mathrm{CCl}_{4}\right)$

3a. LDPE (TCE)

$$
\frac{\mathrm{nb} \mathrm{CHCl}}{\mathrm{nb} \mathrm{CH}_{2}}
$$

1b. $\mathrm{LDPE}\left(\mathrm{CCl}_{4}\right)$

2b. HDPE $\left(\mathrm{CCl}_{4}\right)$

3b. LDPE (TCE)
As poly(vinylidene chloride) (PVDC) structures cannot be changed into $\alpha_{\text {II }}$ structure by photochlorination at room temperature ${ }^{6}$ the steps (1) $\left(1^{\prime}\right)$ are the more likely to occur. This rearrangement mechanism takes place at room temperature only with the CPE samples produced from a branched polyethylene. The chain-breakages occurring along with it "redeploy" the chlorinated chains, i.e., the $T$-conformation proportion begin to increase again, (compare Figure 12 and Figure 13 of Part I of this series ${ }^{8}$ ) which enables the dehydrochlorination process to be an easy one.

When the saturation level is reached, after the minimum scheduled time, the $T$-conformation proportion is higher in the chains of the CPE sample produced from the linear poly- ethylene than in the CPE sample produced from the branched parent polymer: therefore one can state that the $-\mathrm{CCl}_{2}-$ units of some $\beta_{\text {II }}$ (- $\mathrm{CHCl}-\mathrm{CH}_{2}-\mathrm{CCl}_{2}-$ ) structures ruling the rearrangement mechanism have a connection with the former branching points of the parent polymer. The $\equiv \mathrm{CCl}$ - units produced from a tertiary-carbon atom are less stable, under UV beams, than those produced from a secondarycarbon atom.

\section{Influence of the Chlorination Temperature and the Chlorination Medium}

Figure 4 shows that the occurrence of the rearrangement mechanism described above is favored by chlorination temperatures only slightly higher than room temperature, when the reaction is carried out in $\mathrm{CCl}_{4}$ medium, while it does not take place in TCE medium even at $100^{\circ} \mathrm{C}$ or $130^{\circ} \mathrm{C}$. TCE $(1,1,2,2$-tetrachloroethane) reacts with the UV beams and the chlorine radicals to give chlorinated by-products. One of these by-products is 1,1,2,2-tetrachloroethylene or perchloroethylene (PCE) $\left(\mathrm{CCl}_{2}=\mathrm{CCl}_{2}\right){ }^{6}$ Comparative UV spectroscopic studies of a pure TCE sample and of a photochlorinated one showed that the latter absorbs the UV wavelengths under $400 \mathrm{~nm}$ with a maximum of absorption at about $290 \mathrm{~nm} .^{6}$ This phenomenon is enhanced when the TCE is photochlorinated between the $50-70^{\circ} \mathrm{C}$ range. ${ }^{6}$ Other authors ${ }^{14}$ have stated only that PCE absorbs the UV beams under $290 \mathrm{~nm}$.

Therefore it seems that the UV wavelengths under $290 \mathrm{~nm}$ are probably the ones which supply the energy necessary for the occurrence of the rearrangement process. One can notice that the homolytic split of a hydrochloric acid $(\mathrm{HCl})$ molecule requires an energy of $107 \mathrm{kcal},{ }^{15}$ i.e., a UV wavelength of $265 \mathrm{~nm}$.

When the photochlorination is carried out in a suitable solvent $\left(\mathrm{CCl}_{4}\right)$ with a $\mathrm{UV}$ device supplying the proper wavelengths and with a chlorination temperature above $20^{\circ} \mathrm{C}$, it is difficult to descriminate the rearrangement mech- 
anism from the substitution and dehydrochlorination-chlorination ones.

\section{Influence of Oxygen}

Scientists dealing with PVC chlorination technology know that oxygentraces inhibit the chlorination reaction. In order to avoid this inhibition, the chlorination medium is freed from oxygen before the beginning of the chlorination reaction by a nitrogen gas flow for 30 min. Nevertheless, the CPE samples infrared spectra, especially for samples chlorinated to saturation level $(73 \%)$ in $\mathrm{CCl}_{4}$ medium, show a keto-oxygen band at $1740-1760 \mathrm{~cm}^{-1}$ which was present before the recovering of the CPE samples from the chlorination mixtures by methyl alcohol $(\mathrm{MeOH})$ precipitation. A previous study ${ }^{8}$ showed that the carbonyl groups are localized at the ends of the chlorinated chains.

This keto-oxygen band at $1740-1760 \mathrm{~cm}^{-1}$ can arise either from the action of the solvent's oxygen occlusions or from the action of the remaining polymerization catalyst system (oxygenated compounds) of the initial polyethylene samples. When a pure nitrogen gas flow $\left(\mathrm{N}^{48}\right)$ is used for the degassing operation, the 1740$1760-\mathrm{cm}^{-1}$ band does not appear on the infrared spectra of CPE samples photochlorinated in $\mathrm{CCl}_{4}$ medium. Therefore one can state that the oxygen occlusions in the chlorination medium are responsible for the carbonyl group formation through these two probable mechanisms.

(a) Direct Action of Ozone. In the presence of the UV beams, oxygen traces can give ozone which will react with some double bonds arising from the previous described dehydrochlorination processes to give ozonide:<smiles>CC=CC(=O)C1OOC(C)O1</smiles>

Such a structure cannot be stable owing to the global conformation of the chlorinated polymeric chains and the presence of numerous chlorine radicals; it will change into acylchloride, e.g.,

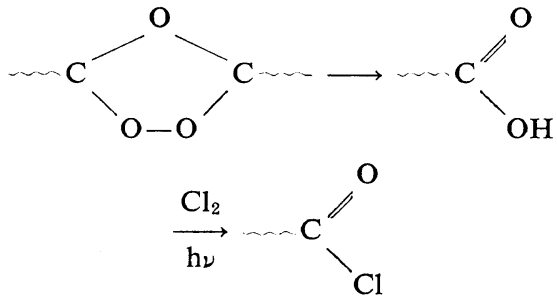

(b) Action of Carbonylchloride or Phosgene. The ozone made from the oxygen traces can give the so-called "native" oxygen, a very reactive radical:

$$
\mathrm{O}_{3} \stackrel{\mathrm{h} \nu}{\longrightarrow} \mathrm{O}_{2}+\mathrm{O} .
$$

The radical will react with trichlorocarbon radical $\left(. \mathrm{CCl}_{3}\right)$ to give phosgene:<smiles></smiles>

From phosgene will arise an acylchloride radical $(. \mathrm{C}-\mathrm{Cl})$ which could react with a chlo-<smiles>[CH]=O</smiles>

rinated polymeric radical to give chlorinated chains ended by acyl-chloride groups.

The $1740-1760-\mathrm{cm}^{-1}$ band observed in the spectrum of a CPE sample, before the $\mathrm{MeOH}$ precipitation, can be assigned to the acylchloride group.

When the chlorinated product is recovered from the chlorination medium, by $\mathrm{MeOH}$ precipitation, the acylchloride group is changed into a methyl acetate, the methyl group of which is responsible for the $1380-\mathrm{cm}^{-1}$ band of some CPE samples. ${ }^{8}$

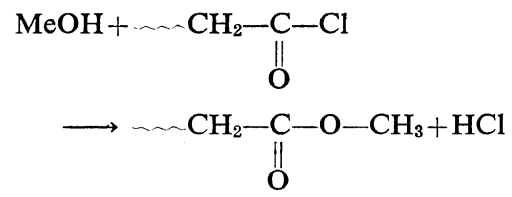

Although the keto-oxygen atom of either an acetate group or an acylchloride group give an infrared band at $1740-1760 \mathrm{~cm}^{-11}$ it is reasonable, owing to the recovering method of the chlorinated product, to consider that acetate groups are mainly responsible for the ketooxygen absorption band revealed by the infrared spectra of CPE samples. 
Chain-breakages are still numerous in the CPE when the formation of the keto-oxygen atom is impeded by an $\mathrm{N}^{48}$-degassing operation before the chlorination reaction. The $\overline{\mathrm{DP}}_{n}$ of the CPE sample so obtained is equal to the $\overline{\mathrm{DP}}_{n}$ of a CPE sample prepared in the same conditions but without $\mathrm{N}^{48}$-degassing process, which indicates that the appearance of the carbonyl groups is not responsible for the chainbreakages. Therefore the second mechanism, which acts through a phosgene-step, is the more likely to occur.

\section{CONCLUSIONS}

Many studies of CPE under various conditions $s^{5-8,11,12}$ enable us to draw the following conclusions:

Three main mechanisms rule the photochlorination and thermal chlorination of polyethylene:

$\left(1^{\circ}\right)$ Substitution of the hydrogen atoms by chlorine atoms.

$\left(2^{\circ}\right)$ Dehydrochlorination principally of the long PVC syndiotactic sequences TTTT produced from the former mechanism followed by rechlorination of the double bonds.

$\mathrm{Up}$ to $64-\%$ chlorine content by weight in thermal chlorination or up to $68-\%$ in photochlorination, the first mechanism is the dominant process. From this interval $(64-68-\%)$ to the saturation level $(73-\%)$ there is a competition between the first and the second mechanisms; when the second prevails polymeric chainbreakages are numerous and the ratio, $\mathrm{nb} \mathrm{CHCl}$ / $\mathrm{nb} \mathrm{CH}_{2}$, is high.

These two mechanisms are the only ones, if the chlorination scheduled time necessary to reach the saturation level $(73-\%)$ is not overrun. In that case, a third mechanism takes place.

$\left(3^{\circ}\right)$ Dehydrochlorination of the $-\mathrm{CCl}_{2}-$ $\mathrm{CH}_{2}-\mathrm{CHCl}-\mathrm{CH}_{2}-\mathrm{CCl}_{2}-$ structures, which are formed principally by the first mechanism from heterotactic polyvinyl tetrads $T T G^{\prime} T$ and $T T G T$ and syndiotactic polyvinyl tetrads $T T T T$ and TTGG. This dehydrochlorination is followed by a rehydrochlorination (rearrangement mechanism) which leads to the $-\mathrm{CCl}_{2}-\mathrm{CH}_{2}-\mathrm{CHCl}-$ $\mathrm{CHCl}-\mathrm{CHCl}-$ structures.

The characteristics of this rearrangement process are the decrease of the $\overline{\mathrm{DP}}_{n}$ and the increase of the ratio, $\mathrm{nb} \mathrm{CHCl} / \mathrm{nb} \mathrm{CH}_{2}$, while the chlorine to carbon ratio, $\mathrm{Cl} / \mathrm{C}$, is constant and equal to unity.

In the case of overrunning the scheduled chlorination time necessary to reach the 73-\% chlorine content by weight the rearrangement mechanism occurs especially if the reaction is carried out in an inert solvent, which does not react with the ultraviolet beam and the chlorine atoms to give chlorinated by-products. ${ }^{6}$ In our study carbon tetrachloride $\left(\mathrm{CCl}_{4}\right)$ was such a suitable solvent.

In $\mathrm{CCl}_{4}$ medium, when the photochlorination temperature is above $20^{\circ} \mathrm{C}$ this rearrangement mechanism rarely occurs with chlorinated HDPE (linear polymer) but occurs to a larger extent with chlorinated LDPE (branched polymer). This fact has undoubtedly a connection with the branchings of the initial LDPE.

When a chlorine content by weight of 56$61-\%$ is obtained, we postulate that the maximum chlorine level (73-\%) can be easily reached if during the preceding substitution mechanism the polyvinyl syndiotactic and isotactic sequences have alternated regularly to give a maximum of polyvinyl heterotactic tetrads.

The differences between the photochlorination process and the thermal-chlorination process are linked to the conformational and configurational changes occurring in the chlorinated polymer chains.

In the photochlorinated process the PVC syndiotactic sequences TTTT and the PVC isotactic sequences TGTG, which appear up to the 5661-\% chlorine content, are short ones. They alternate regularly to give numerous PVC heterotactic tetrads; $T T T G, T T G T$, and $T T G^{\prime} T$.

In the thermal-chlorination process the conformations of the vinyl sequences depend on the nature of the initial polyethylene. The branchings of the LDPE favor the appearance of long PVC isotactic sequences TGTG, which alternate with short PVC syndiotactic sequences TTTT to give a few PVC heterotactic tetrads TTTG (at the 61-\% chlorine content). In the case of the HDPE (linear polymer) the PVC sequences are long syndiotactic TTTT and long isotactic TGTG ones which alternate to give a few PVC heterotactic tetrads TTTG, TTGT, and $T T G^{\prime} T$ at the 56-\% chlorine content. 
At the 56-61-\% chlorination step, the more polyvinyl heterotactic tetrads contains, the higher can be its subsequent chlorine content by weight; the chlorination of these polyvinyl heterotactic tetrads must be almost complete (about 64$68-\% \mathrm{Cl}_{2}$ ) before the beginning of the chlorination of the polyvinyl sequences TTTT. Owing to the growing stiffness of the 64-68-\% CPE samples, ${ }^{12}$ the chlorination reaction can reach the maximum chlorine-content level (73-\%) only if the energy supplied by the catalyst system enables the short polyvinyl syndiotactic sequences TTTT to rotate into easily chlorinated TTGG ones. The thermal-chlorination process does not fit this important condition and when the long PVC syndiotactics sequences are completely chlorinated a chlorine content limit is obtained $(65-67-\%)$ below the maximum chlorine content level $(73-\%)$.

\section{REFERENCES}

1. M. L. Huggins, G. Natta, N. Desreux, and H. Mark, J. Polym. Sci., 56, 153 (1962).

2. B. M. Quenum, P. Berticat, J. L. de la Pena, and J. Millan, Eur. Polym. J., 10, 157, (1974).

3. V. R. Allen and L. F. Thomson, Appl. Polym. Symp., 10, 131 (1969).
4. V. R. Allen and R. D. Young, J. Polym. Sci. Part A-1, 8, 3129 (1970).

5. B. M. Quenum, P. Berticat, and Q. T. Pham, Eur. Polym. J., 7, 1527 (1971).

6. B. M. Quenum, P. Berticat, and Q. T. Pham, ibid., 9, 777 (1973).

7. G. Humbert, B. M. Quenum, P. Berticat, Q. T. Pham, and G. Vallet, Makromol. Chem., 175 1597 (1974).

8. B. M. Quenum, P. Berticat, and G. Vallet, Polymer J., 7, 277 (1975).

9. P. Berticat, J. Chim. Phys., 64, 887 (1967).

10. J. Packer and V. Vaughan, "A Modern Approach to Organic Chemistry," Oxford Univ. Press, Oxford, 1958.

11. B. M. Quenum, P. Berticat, and G. Vallet, Polymer J., 7, 300 (1975).

12. G. Humbert, B. M. Quenum, P. Berticat, and G. Vallet, Makromol. Chem., 175, 1611 (1974).

13. J. Millan, M. Carranza, and J. Gusman, IUPAC Symposium on Macromolecules, Helsinki, 1972, Preprint IV, 21 Vol. 5.

14. U. V. Atlas, Vol. VIII Butterworths, Verlag Chemie.

15. Coleman Weicksel, Mod. Plast., 39, 244 (1959).

16. K. Nakanishi, "Infrared Absorption Spectroscopy,'” Nankodo Co. Ltd., Tokyo, 1964, p 188.

17. P. Lissac, P. Berticat, and Q. T. Pham, J. Macromol. Sci. Chem., A5, 901 (1971). 